\title{
Asthma in adolescents: A randomized, controlled trial of an asthma program for adolescents and young adults with severe asthma
}

\author{
Robert L Cowie MD, Margot F Underwood BN, Cinde B Little RT, \\ Ian Mitchell MB ChB, Sheldon Spier MD, Gordon T Ford MD
}

RL Cowie, MF Underwood, CB Little, I Mitchell, S Spier, GT Ford. Asthma in adolescents: A randomized, controlled trial of an asthma program for adolescents and young adults with severe asthma. Can Respir J 2002;9(4):253-259.

BACKGROUND: Asthma is common and is often poorly controlled in adolescent subjects.

OBJECTIVE: To determine the impact of an age-specific asthma program on asthma control, particularly on exacerbations of asthma requiring emergency department treatment, and on the quality of life of adolescents with asthma.

METHODS: The present randomized, controlled trial included patients who were 15 to 20 years of age and had visited emergency departments for management of their asthma. The interventional group attended an age-specific asthma program that included assessment, education and management by a team of asthma educators, respiratory therapists and respiratory physicians. In the control group, spirometry was performed, and the patients continued to receive usual care from their regular physicians. The outcomes were assessed by a questionnaire six months after entry into the study.

RESULTS: Ninety-three subjects entered the study and were randomly assigned to the intervention or control group. Of these, only 62 patients were available for review after six months. Subjects in both the control and the intervention groups showed a marked improvement in their level of asthma control, reflected primarily by a $73 \%$ reduction in the rate of emergency department attendance for asthma. Other indexes of disease control, including disease-specific quality of life, as assessed by questionnaires, were improved. There was, however, no discernible difference between the subjects in the two groups, with the exception of an improvement in favour of the intervention group in the symptom (actual difference 0.7, $\mathrm{P}=0.048$ ) and emotional (actual difference 0.8, $\mathrm{P}=0.028$ ) domains of the asthma quality of life questionnaire. The overall quality of life score favoured the intervention group by a clinically relevant difference of 0.6 , but this difference did not reach statistical significance $(\mathrm{P}=0.06)$.

CONCLUSIONS: Although all subjects demonstrated a significant improvement in asthma control and quality of life, the improvement attributable to this intervention was limited to two domains in disease-specific quality of life.

Key Words: Adolescent; Asthma; Randomized controlled trial

Résumé à la page suivante

Departments of Medicine and Paediatrics, University of Calgary, Alberta

Correspondence and reprints: Dr RL Cowie, 3330 Hospital Drive NW, Calgary, Alberta T2N 4N1. Telephone 403-220-8981,

fax 403-270-8928, e-mail cowie@ucalgary.ca 


\section{L'asthme chez les adolescents : essai comparatif aléatoire d'un programme de traitement conçu pour des adolescents et de jeunes adultes souffrant d'asthme grave}

CONTEXTE : L'asthme, maladie fréquente, est souvent peu maîtrisé chez les adolescents.

OBJECTIF : Vérifier l'incidence d'un programme de traitement conçu en fonction de l'âge sur la maîtrise de la maladie, plus précisément sur les exacerbations qui nécessitent une consultation au service des urgences ainsi que sur la qualité de vie des adolescents asthmatiques.

MÉTHODE : L'essai comparatif aléatoire a été mené auprès de patients âgés de 15 à 20 ans, qui avaient dû consulter un médecin à l'urgence pour leurs crises d'asthme. Le groupe expérimental a participé à un programme conçu en fonction de l'âge, qui consistait en l'évaluation et le traitement de la maladie ainsi qu'en l'éducation des jeunes, et ce, par des éducateurs, des inhalothérapeutes et des pneumologues. Dans le groupe témoin, les sujets ont été soumis à une spirométrie et ont reçu les soins usuels. Il y a eu évaluation des résultats au moyen d'un questionnaire six mois après l'admission dans l'étude.

RÉSULTATS : Au total, 93 patients ont participé à l'étude et ont été dirigés au hasard vers le groupe témoin ou le groupe expérimental. De ce nombre, 62 seulement ont été revus pour le contrôle au bout de six mois. Les sujets dans les deux groupes ont connu une amélioration sensible de la maîtrise de l'asthme, qui s'est traduite surtout par une diminution de $73 \%$ du taux de consultations au service des urgences. Nous avons également noté une amélioration d'autres indices de maîtrise de la maladie, notamment de la qualité de vie des asthmatiques. Toutefois, nous n'avons pas enregistré de différence notable entre les sujets des deux groupes, si ce n'est une amélioration en faveur du groupe expérimental, relevée dans les parties du questionnaire sur la qualité de vie traitant des symptômes (différence réelle : 0,$7 ; \mathrm{P}=0,048$ ) et de l'affectivité (différence réelle : 0,8; $\mathrm{P}=0,028$ ). Dans l'ensemble, le score relatif à la qualité de vie a favorisé le groupe expérimental, mais l'écart, même s'il s'est avéré cliniquement significatif $(0,6)$, ne s'est pas montré statistiquement significatif $(P=0,06)$. CONCLUSION : Bien que tous les sujets aient connu une amélioration sensible de la maîtrise de l'asthme et de la qualité de vie, l'amélioration attribuable à l'intervention s'est limitée à deux domaines de l'échelle de la qualité de vie propre aux asthmatiques.
A sthma is the most common chronic disease in adolescents (1). The disease is often neglected in this age group, possibly, in part, because of the perception that children outgrow asthma. The data do not support this view $(2-4)$, and Levison et al (5) has said that it is not the asthma, but the pediatrician, that is outgrown (5). Adolescents and young adults with chronic diseases are considered to be difficult to treat because they deny their symptoms, are poorly adherent to therapy and fail to make the transition from pediatric to adult medical caregivers (2). In asthma, adolescents and young adults have been identified as being at an increased risk of death from their disease (6). There is also concern that the hiatus in their care could result in poor career decision-making, and that irreversible changes to their airways, as a result of poor treatment, could set an unfavourable course for their disease in later life (7). There is evidence, for example, that adolescents display risk behaviour, and in those with asthma, this may translate into an increased likelihood of smoking (8).

We were particularly concerned about the subset of adolescents and young adults with asthma who carried the additional risk factor of repeated visits to emergency departments (EDs), signalling a pattern of severe disease and crisis management. In this study, we developed an age-specific program for individuals who were 15 to 20 years of age with asthma to determine whether this would have a favourable effect on the control of their disease and on their quality of life. We believed that participation in an age-specific asthma program would result in an improvement in their asthma control and in their quality of life. We defined improved control as a decrease in the number of ED visits and admissions to hospital for asthma, fewer asthma symptoms and less time away from school or work.

\section{METHODS}

The regional institutional review boards and the Conjoint Health Research Ethics Board of the University of Calgary,
Alberta gave approval to conduct the study and to extract, from the records of the EDs in Calgary, Alberta, the names and telephone numbers of individuals between the ages of 15 and 20 years who had received urgent treatment for asthma. A respiratory therapist with experience in childhood asthma was employed to contact each person who fulfilled these two criteria for inclusion in the study. People who were contacted were advised of the study, in which they would be randomly assigned to either participate in the asthma program or continue with routine medical care. Subjects who agreed to participate were then randomly assigned to the intervention (Young Adult Asthma Program [YAAP]) group or to the control group at the time of the initial telephone contact. Subjects were randomly assigned by opening consecutively numbered, sealed envelopes, in which the subject's allocation was indicated. The coordinator had a small number of sealed envelopes that she was required to open sequentially. The randomization codes were generated by one of the investigators and were not available to the coordinator. The process did not produce a predictable order of allocation, and no adjustment of allocation could be made after the subject had been enrolled. The two groups had no contact with each other.

The subjects in the YAAP group were given an appointment to attend the program, which was held between 16:00 and 20:00 to accommodate those having school or work commitments. The site of the YAAP was relatively central in the city, and ample free parking was available. Subjects were invited to attend the YAAP for an initial visit and one follow-up visit. The YAAP was staffed by one or two asthma educators, respiratory therapists who performed the spirometry and assessed inhaler technique, and a respiratory physician or pediatrician. At the YAAP, each subject was assessed individually, although there was opportunity for interaction with other attendees and with any accompanying individuals. Initial questionnaires were completed to document the 
duration of the subjects' asthma, the risk factors to which they were exposed, their treatment and their level of asthma control. The questionnaire contains direct questions about asthma and has been used in the Calgary Asthma Program to assess over 3000 individuals with the disease. The data obtained from the questionnaire appear to correlate well with other findings related to asthma severity and control (9). The self-reported information contained in this questionnaire and a quality of life questionnaire (10) were the sources of the data used to assess and compare the two groups of subjects in this study. The participants were initially assessed with spirometry before and after treatment with a beta 2 -agonist. Their inhaler technique was assessed, and instruction was given. The subjects were provided with general information about asthma and its management based on the Canadian asthma consensus guidelines (11). Emphasis was placed on the use of inhaled corticosteroids and the appropriate use of bronchodilators. The discussion included information about asthma-inducing and triggering agents, with an emphasis on household animals, smoking and secondhand smoke. An opportunity was given for the subject to express any concerns or fears that he or she had about his or her asthma, and to identify their expectations from his or her attendance at the YAAP. The relevance of asthma in the context of the subject's career or proposed careers was also discussed. The subject was seen by a physician trained in asthma management, who confirmed the diagnosis, discussed and adjusted therapy, and reviewed the need for disease monitoring and an action plan. The duration of the session varied from 90 to $120 \mathrm{~min}$ depending on the needs and baseline knowledge of the subject. After their attendance at the program, a report was sent to their regular family physician containing details about their disease, information about the instructions that they had been given and changes in their medication. When an action plan was given, a copy was included in the report to the physician. Each of the subjects in the intervention group was given an appointment to return to the YAAP for a follow-up visit with the full YAAP team to review his or her progress and relevant aspects of asthma management.

The subjects in the control group were asked to attend, at a time convenient to them that was not during the time allocated to the YAAP group, to provide their consent to participate in the study and to complete their initial assessments. They were each assessed using spirometry before and after treatment with a bronchodilator, and in the process, received instruction in inhaler technique. They also completed the same asthma and quality of life questionnaires as the YAAP group. All of the control subjects were seen by the same respiratory therapist who directed the YAAP. The subjects in the control group were advised to visit their regular physician, as is the standard of care for people with asthma who have required treatment in an ED. No other instruction or information was provided.

Three months after random assignment, all participants were sent a second copy of the asthma and quality of life questionnaires to complete and return by mail. Six months after random assignment, they were sent a third copy of the asthma and quality of life questionnaires. Those who did not return their completed questionnaires were contacted by telephone and encouraged to complete their questionnaires. The data presented are from the the third questionnaire and quality of life assessment from the intervention (YAAP) and control groups.

For the purpose of the present study, asthma control was defined as: not needing ED treatment or hospital admission for asthma in the preceding six months; not missing time from work or school because of asthma in the preceding three months; not waking at night because of asthma in the preceding week; and not needing to use reliever (short-

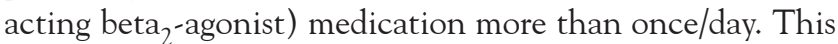
definition of control was based on the criteria used in the Canadian asthma consensus guidelines (11), which were in use at the time of the study, with a more generous allowance with regard to beta 2 -agonist use.

\section{Analysis}

The primary outcome of interest was the use of EDs for the management of asthma in the six months after entry to the study. Other outcomes included an assessment of diseasespecific quality of life and general measurements of asthma control. Data were analyzed using $\chi^{2}$ analysis or Fisher's exact test and by Student's $t$ test or the Kruskal-Wallis test for two groups using the statistical component of Epi Info Version 6 (Centers for Disease Control and Prevention, Atlanta, Georgia, and World Health Organization, Geneva, Switzerland). The sample size was calculated using Epi Info Version 6 for a cohort study and was based on an earlier, unpublished study that showed a reduction in the number of $\mathrm{ED}$ visits for asthma to one-quarter of that before the intervention. On that basis, a sample of 20 subjects in each of the two groups should have $80 \%$ power to show an additional reduction to one-quarter of the number of $\mathrm{ED}$ visits by the intervention group compared with the control group. Because of uncertainty about the pattern of ED use in this adolescent population and to allow for an anticipated high dropout rate, the study protocol was designed to recruit 65 subjects into each of the two groups. The analysis was based on the principle of intention-to-treat, and account was not taken of the extent to which those in the intervention group actually participated in the YAAP beyond their initial visit.

\section{RESULTS}

ED records were collected over a period of one year, and subjects were enrolled in the study over a period of eight months. Three hundred fifty-nine subjects between 15 and 20 years old who had attended one of Calgary's EDs for treatment of asthma were included in the study. The first 254 subjects were included in the study population. Only 130 of the 254 subjects could be contacted at the telephone number that they had provided at their visit to the ED and agreed to participate. All 130 subjects were randomly assigned to either the YAAP or the control group, but only 93 attended their initial assessment and were enrolled in the study. Enrolment occurred within six months (mean 76 days) of their index 
TABLE 1

Study entry characteristics of the subjects in the intervention (Young Adult Asthma Program [YAAP]) and control groups of a randomized, controlled trial studying the impact of an age-specific asthma program

\begin{tabular}{|c|c|c|c|}
\hline & $\begin{array}{l}\text { Control group } \\
(n=33)\end{array}$ & $\begin{array}{l}\text { YAAP group } \\
(n=29)\end{array}$ & $\mathbf{P}$ \\
\hline Age in years (mean $\pm S D)$ & $17.1 \pm 1.75$ & $17.4 \pm 1.99$ & 0.5 \\
\hline Sex (female/male) & $24 / 9$ & $20 / 9$ & 0.7 \\
\hline Number of admissions for asthma in year before study entry & 9 & 7 & 0.4 \\
\hline Number of subjects admitted for asthma in year before study entry (\%) & $9(27)$ & $7(24)$ & 0.8 \\
\hline Number of emergency department visits for asthma in year before study entry & 99 & 93 & 0.8 \\
\hline Number of intensive care unit admissions for asthma in group history & 5 & 2 & 0.3 \\
\hline Number of subjects using an inhaled corticosteroid (\%) & $26(79)$ & $21(72)$ & 0.6 \\
\hline Times per week waking with asthma (mean \pm SD) & $2 \pm 2.7$ & $2 \pm 2.6$ & 0.6 \\
\hline Number of subjects waking with asthma (\%) & $19(58)$ & $16(55)$ & 0.9 \\
\hline Number of doses of a beta ${ }_{2}$-agonist per day (mean \pm SD) & $4 \pm 2.6$ & $3 \pm 2.0$ & 0.05 \\
\hline Number of subjects using beta ${ }_{2}$-agonist more than once per day $(\%)^{\star}$ & $27(82)$ & $21(72)$ & 0.4 \\
\hline Per cent predicted forced expiratory volume in $1 \mathrm{~s}$ (mean \pm SD) & $78 \pm 16.7$ & $85 \pm 14.6$ & 0.5 \\
\hline Quality of life $(\text { mean } \pm S D)^{\dagger}$ & $4.6 \pm 1.38$ & $4.8 \pm 1.13$ & 0.5 \\
\hline
\end{tabular}

*Usual dose equivalent to salbutamol $200 \mu \mathrm{g}$; ${ }^{\dagger}$ Quality of life scores range from 1 for poor to 7 for the best quality (10)

visit to an ED. There was no significant difference in the mean delay until enrolment from the index ED visit between the control group (68 days) and the YAAP group (84 days). Seventy-nine of the 93 subjects completed the three-month questionnaire, and 62 of the subjects (29 in the YAAP group and 33 in the control group) completed their six-month questionnaires and quality of life assessments. At three months, four of the 32 YAAP subjects and 16 of the 47 control subjects reported that they had visited an ED for asthma treatment $(\mathrm{P}=0.03)$. Although the three-month data do show a significant reduction in the number of $\mathrm{ED}$ visits in the YAAP group compared with the control group, the sixmonth data have been selected for this report as representative of a more stable and relevant impact of the intervention.

A comparison between the 62 subjects who completed the study and the 31 subjects who completed the initial assessment but could not be contacted for the six-month follow-up showed that the two groups did not differ significantly with regard to the initial severity of their disease and the frequency of their ED visits or hospital admissions.

The data comparing the 29 subjects in the YAAP group and the 33 subjects in the control group who completed their six-month follow-up visits - at the time of their entry to the study - are presented in Table 1 . The entry data show that the two groups were similar in all relevant respects. With regard to their quality of life assessment, the two groups did not differ as a whole nor with regard to each of the four domains (10). At six months after entry, there were no significant differences between the groups with regard to their disease control and management (Table 2). Seven subjects from the control group and nine subjects from the YAAP group had increased the dose of their inhaled corticosteroid between the initial and the six-month assessment $(\mathrm{P}=0.4)$. Twelve subjects from the control group and nine subjects from the YAAP group decreased their use of inhaled corticosteroids in that interval $(\mathrm{P}=0.7)$. The average dose of inhaled corticosteroid (beclomethasone dipropionate equivalent) for those using inhaled corticosteroids was $729 \mu \mathrm{g}$ for the control group and $668 \mu \mathrm{g}$ for the YAAP group $(\mathrm{P}=0.7)$

The YAAP group had significantly higher scores than the control group in two domains of the quality of life assessment. The YAAP group also showed a trend toward a better overall quality of life assessment (Table 3).

Both groups showed a significant improvement in terms of the number of $E D$ visits for asthma $(P<0.01)$, quality of life scores $(\mathrm{P}=0.0001)$, number of admissions for asthma $(\mathrm{P}=0.01)$ and time off from work or school $(\mathrm{P}<0.01)$ from the time of entry to the study to six months after entry. Data for the 161 (of 254) subjects who attended an ED for asthma, but did not enter the study, were limited, for ethical reasons, to a review of the ED records. The review suggested that these 161 subjects also demonstrated a reduction in ED use to a degree that did not differ significantly from that of the 93 participants.

Of possible interest was the finding that $53 \%$ of the 93 subjects who entered the study smoked or lived with a smoker: $29 \%$ of the female subjects and $7 \%$ of the male subjects smoked $(P=0.02)$. Sixty-four per cent of the subjects had an animal in their home. With regard to smoking or animals in the home, there was no difference between prestudy and poststudy, or YAAP and control group findings.

A questionnaire was sent to the subjects who had been allocated to attend the YAAP, asking them to rank the YAAP anonymously. The mean ranking of the intervention in terms of help with the subjects' worries and fears about asthma was 4.7 of a total favourable score of 5.0. Other scores were 4.9 of 5.0 for helpfulness in answering ques- 
TABLE 2

Asthma control, six months after study entry, of the subjects in the intervention (Young Adult Asthma Program [YAAP]) and control groups of a randomized, controlled trial studying the impact of an age-specific asthma program

\begin{tabular}{|c|c|c|c|}
\hline Asthma control characteristics during the six-month study period & $\begin{array}{c}\text { Control group } \\
(n=33)\end{array}$ & $\begin{array}{l}\text { YAAP group } \\
(\mathrm{n}=29)\end{array}$ & $\mathbf{P}$ \\
\hline Number of subjects admitted for asthma & 4 & 0 & $0.6^{*}$ \\
\hline Number of admissions for asthma & 5 & 0 & 0.06 \\
\hline Number of subjects visiting the emergency department for asthma & 13 & 9 & 0.6 \\
\hline Number of emergency department visits for asthma & 21 & 12 & 0.3 \\
\hline Number of intensive care unit admissions for asthma & 0 & 0 & NS \\
\hline Number of subjects using an inhaled corticosteroid & 24 & 22 & 0.8 \\
\hline Dose of inhaled corticosteroid & $729 \mu \mathrm{g} / \mathrm{day}$ & $668 \mu \mathrm{g} / \mathrm{day}$ & 0.7 \\
\hline Times per week waking with asthma (mean \pm SD) & $2 \pm 2.9$ & $1 \pm 2.2$ & 0.2 \\
\hline Number of doses of a beta ${ }_{2}$-agonist per day $(\text { mean } \pm S D)^{\dagger}$ & $3 \pm 2.6$ & $2 \pm 2.2$ & 0.2 \\
\hline Number of missed work or school days (mean \pm SD) & $1.3 \pm 2.82$ & $1.6 \pm 4.65$ & 0.4 \\
\hline Number of subjects missing work or school & 8 & 4 & 0.3 \\
\hline
\end{tabular}

*Fisher's two-tailed test; other analyses by $\chi^{2}$ analysis or Student's t test for independent samples; †Usual dose equivalent to salbutamol $200 \mu g$. NS Not significant

tions, 4.4 of 5.0 for the extent to which the YAAP met their expectations and 4.8 of 5.0 for their willingness to recommend it to their friends with asthma.

\section{DISCUSSION}

With the exception of two domains in the quality of life assessment (10) - symptoms and emotions - there was no demonstrable effect of the YAAP intervention. There was a trend toward improved control of asthma and overall quality of life scores in the YAAP group, which might have been significant if the intended number of subjects had been enrolled and retained. The extent of the improvement would be disappointing, given the labour-intensive nature of the intervention. The respiratory therapist who managed the study spent approximately $10 \mathrm{~h} /$ week contacting those subjects who were scheduled to attend the YAAP and rescheduling appointments for those who had missed their appointments. Even with this careful preparation, attendance seldom reached 50\%. Sixteen to 24 person-hours were donated by the program personnel at each session of the YAAP - often for only one or two attendees. Our experience contrasted with that of others, who have concluded that adolescents wish to manage their health, and that they need and seek information to do this effectively (12-14).

The absence of a significant improvement in asthma control attributable to the age-specific asthma program in this study is disappointing. We used an intention-to-treat analysis, but 35 of the 43 subjects (81\%) who attended the YAAP did complete the intervention by returning for their second visit. The intention was to conclude the education component of the YAAP by providing a written action plan. This was the case in all but three subjects, in whom either the subject or the physician decided that a plan was not appropriate.

There may be concern about the quality of the YAAP, and although all of the physicians involved in the study had experience in dealing with adolescents in their practices, it
TABLE 3

Quality of life (mean \pm SD), six months after study entry, of the subjects in the intervention (Young Adult Asthma Program [YAAP]) and control groups of a randomized, controlled trial studying the impact of an age-specific asthma program

\begin{tabular}{lccl}
\hline $\begin{array}{l}\text { Quality of life } \\
\text { domain }\end{array}$ & $\begin{array}{c}\text { Control group } \\
(\mathbf{n}=\mathbf{3 3})\end{array}$ & $\begin{array}{c}\text { YAAP group } \\
(\mathbf{n}=\mathbf{2 9})\end{array}$ & $\mathbf{P}$ \\
\hline Activity & $5.6 \pm 1.23$ & $5.9 \pm 1.01$ & 0.4 \\
Symptoms & $4.9 \pm 1.41$ & $5.6 \pm 1.28$ & 0.048 \\
Emotional & $5.1 \pm 1.71$ & $5.9 \pm 1.47$ & 0.028 \\
Environmental & $5.2 \pm 1.42$ & $5.8 \pm 1.20$ & 0.13 \\
Overall quality of life & $5.2 \pm 1.40$ & $5.8 \pm 1.10$ & 0.06 \\
\hline
\end{tabular}

Quality of life is measured on a scale of 1 to 7 , with 7 being the best quality (10). A statistically significant difference in score, which is equal to or greater than 0.5 for any of the domains or for the total score, is considered to be clinically significant (19); there was no difference between the two groups for any of the four domains of quality of life or for the overall score on entry to the study

is possible that they and the YAAP could have benefited from specific training (15). We recognized that a peer support group would be an important aspect of the YAAP $(6,16)$, but the adolescents who were approached failed to provide this support, even though the majority of them expressed an interest in developing such a group. We did have the support of several young (18- to 20-year-old) trainee respiratory therapists who attended the YAAP and participated in the assessment and education of the attendees. In other respects, we tried to make the YAAP suitable for the age group of our subjects. An adolescent asthma program, as we perceived it, differed from an adult (and from a pediatric) asthma program largely by the attendance of adolescents only. No other age groups were seen at the YAAP. Refreshments were provided and conformed with the stated taste of adolescents whose opinion we canvassed. Waiting times were minimal because of a very high staff to patient 
ratio, but those who elected to spend more time in the area had access to television and a wide range of general entertainment videotapes. Staff were encouraged to wear casual clothing and be relaxed in demeanour, and young adults were represented in the YAAP staff. The results of our anonymous survey appeared to confirm that the subjects were pleased with the ambience and structure of the YAAP, and with the services that were provided.

Another potential criticism of the present study may be the small proportion of the potential subjects who actually participated in the study. Those included in the study might be considered to represent a compliant subset in which there was little room to demonstrate an improvement above that of a compliant control group. However, review of the status of both groups six months after entry showed that, although improved, their asthma remained poorly controlled: only $23 \%$ demonstrated disease control as defined by the Canadian consensus guidelines (11), and 35\% had continued to use EDs for treatment of exacerbations of their asthma.

It is interesting to note that both groups in our study (both the control and YAAP groups) demonstrated a substantial improvement in their asthma control. It is probable that this reflects regression to the mean rather than an impact from the minimal contact that we had with the control group. This explanation is supported by the limited information available on the nonparticipants, which suggests that they experienced a similar reduction in the number of ED visits. This observation is clearly relevant in the context of interventions relating to asthma - failure to provide a control group could readily result in an erroneous opinion that the intervention was effective.

It is encouraging that $76 \%$ of our subjects claimed to be using an inhaled corticosteroid, and all of those who continued to visit the ED for asthma treatment said that they were taking an inhaled corticosteroid. There was, however, no change in the proportion of subjects using inhaled corticosteroids between the entry and follow-up visits, and no differences in inhaled corticosteroid use were apparent between the intervention and control groups. Inhaled corticosteroid use was based on self-report; self-reported use may exceed actual and appropriate use by approximately threefold (17). It has also been reported that adolescents may be particularly reluctant to use inhaled corticosteroids (18).

We are uncertain of the significance of the increased quality of life in two domains in the YAAP group. The overall quality of life score also showed a trend in favour of the YAAP group that would have been clinically significant (a difference of 0.5 or more in the overall score or in the score for each domain) had it reached statistical significance (19). Others have noted emotional impairment in adolescents with asthma, especially in those with severe disease (20). We hope that, as suggested by Price (6), our intervention may permit our adolescent subjects to "arrive successfully at competent adulthood". Shah et al (16), in their study of an age-specific intervention for adolescents with asthma, found that their subjects showed an improvement in the activities domain, and not in the symptoms and emotional domains. It is also possible that different results would have been obtained if we had been able to use an age-specific quality of life questionnaire (21).

The present study showed a benefit in terms of quality of life, but no sustained benefit in terms of asthma control, of our age-specific and labour-intensive asthma program for adolescents. There is a real need to provide care and advice for children with asthma once they become adolescents. At the very least, a program for adolescents with asthma should serve as a bridge between pediatric and adult care, and should offer advice about smoking and career choice. Physicians need to be aware that asthma is highly prevalent in adolescents who appear not to fit comfortably into most pediatric or adult asthma programs.

ACKNOWLEDGEMENTS: This study was funded by the Alberta Lung Association. No conflict of interest has been identified regarding this study and its authors.

\section{REFERENCES}

1. Rich M, Schneider L. Managing asthma with the adolescent. Curr Opin Pediatr 1996;8:301-9.

2. Roorda RJ. Prognostic factors for the outcome of childhood asthma in adolescence. Thorax 1996;51(Suppl):S7-12.

3. Forero R, Bauman A, Young L, Larkin P. Asthma prevalence and management in Australian adolescents: results from three community surveys. J Adolesc Health 1992;13:707-12.

4. Robson B, Woodman K, Burgess C, et al. Prevalence of asthma symptoms among adolescents in the Wellington region by area and ethnicity. N Z Med J 1993;106:239-41.

5. Levison H, Collins-Williams C, Bryan A, Reilly B, Orange R. Asthma: current concepts. Pediatr Clin North Am 1974;21:951-65.

6. Price J. Issues in adolescent asthma: what are the needs? Thorax 1996;51(Suppl):S13-7.

7. Grol MH, Gerritsen J, Vonk J, et al. Risk factors for growth and decline of lung function in asthmatic individuals up to age 42 years: a 30 year follow-up study. Am J Respir Crit Care Med 1999:160:1830-7.

8. Brook U, Shiloh S. Attitudes of asthmatic and nonasthmatic adolescents towards cigarettes and smoking. Clin Pediatr (Phila) 1993;32:642-6

9. Cowie RL, Underwood MF, Revitt SG, Field SK. Predicting emergency department utilization in adults with asthma: a cohort study. J Asthma 2001;38:179-84.

10. Juniper EF, Guyatt GH, Epstein RS, Ferrie PJ, Jaeschke R, Hiller TK. Evaluation of impairment of health-related quality of life in asthma: development of a questionnaire for use in clinical trials. Thorax 1992;47:76-83.

11. Ernst P, Fitzgerald JM, Spier S. Canadian Asthma Consensus Conference: summary of recommendations. Can Respir J 1996;3:89-100.

12. Slack MK, Brooks AJ. Medication management issues for adolescents with asthma. Am J Health Syst Pharm 1995;52:1417-21.

13. Townsend J, Wilkes H, Haines A, Jarvis M. Adolescent smokers seen in general practice: health, lifestyle, physical measurements and response to antismoking advice. BMJ 1991;303:947-50.

14. Gibson PG, Henry RL, Vimpani GV, Halliday J. Asthma knowledge, attitudes, and quality of life in adolescents. Arch Dis Child 1995;73:321-6.

15. Sanci LA, Coffey CMM, Veit FCM, et al. Evaluation of the effectiveness of an educational intervention for general practitioners in adolescent health care: randomised controlled 
trial. BMJ 2000;320:224-30.

16. Shah S, Peat JK, Mazurski EJ, et al. Effect of peer led programme for asthma education in adolescents: cluster randomised controlled trial. BMJ 2001;322:583-5.

17. Milgrom H, Bender B, Ackerson L, Bowry P, Smith H, Rand C. Noncompliance and treatment failure in children with asthma. J Allergy Clin Immunol 1996;98:1051-7.

18. Price J, Kemp J. The problems of treating adolescent asthma: what are the alternatives to inhaled therapy? Respir Med 1999;93:677-84.
19. Juniper EF, Guyatt GH, Willan A, Griffith LE. Determining a minimal important change in a disease-specific Quality of Life Questionnaire. J Clin Epidemiol 1994;47:81-7.

20. Silverglade L, Tosi D, Wise P, D-Costa A. Irrational beliefs and emotionality in adolescents with and without bronchial asthma. J Gen Psychol 1994;121:199-207.

21. Rutishauser C, Sawyer SM, Bond L, Coffey C, Bowes G. Development and validation of the Adolescent Asthma Quality of Life Questionnaire (AAQOL). Eur Respir J 2001;17:52-8. 


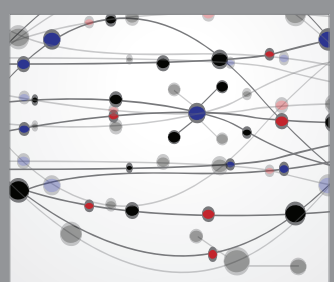

The Scientific World Journal
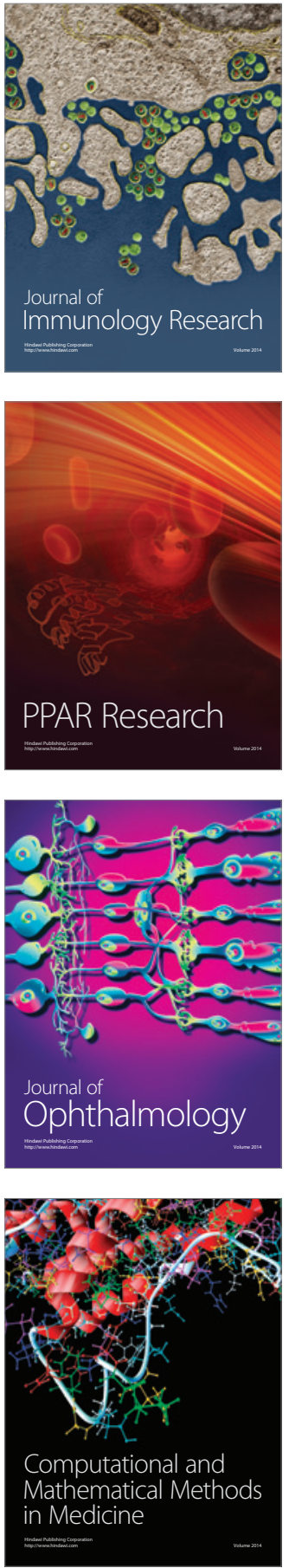

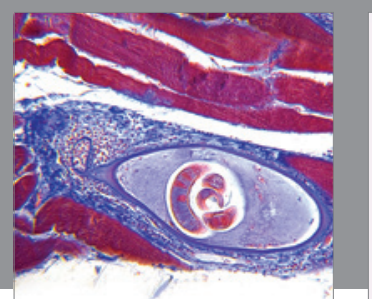

Gastroenterology Research and Practice

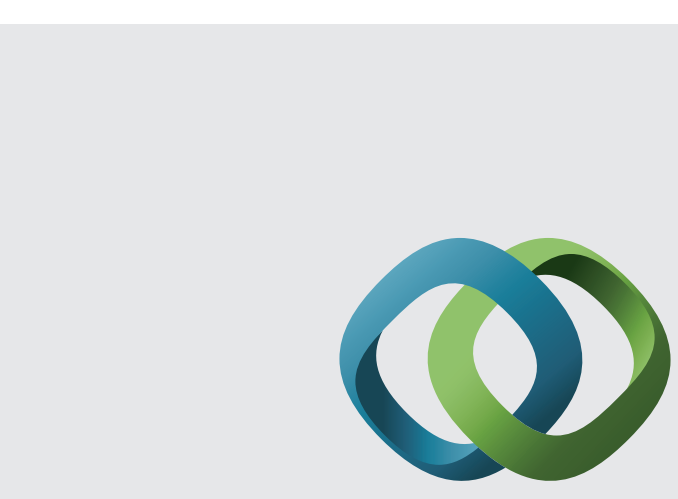

\section{Hindawi}

Submit your manuscripts at

http://www.hindawi.com
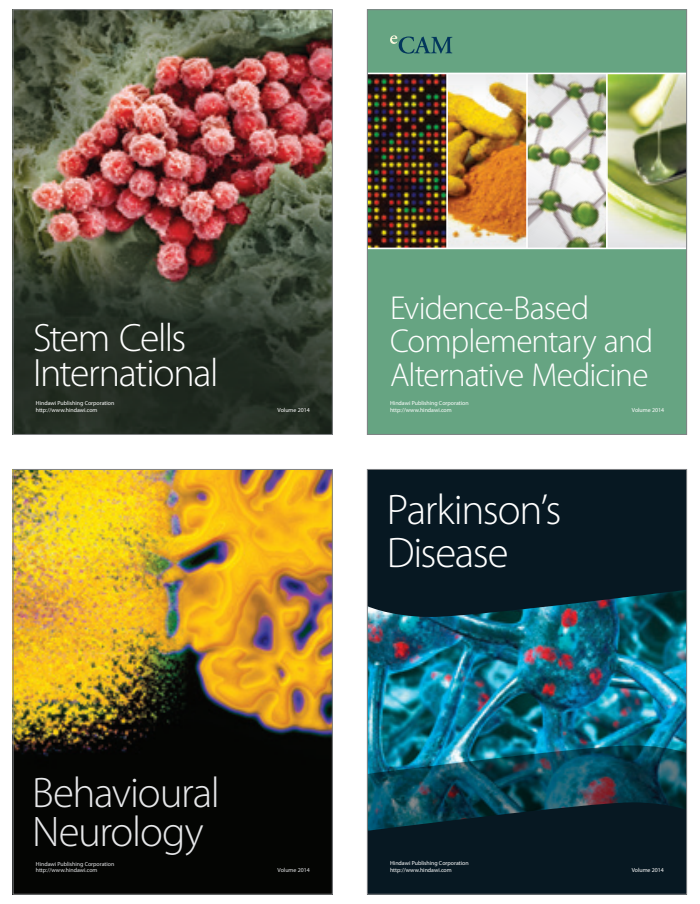
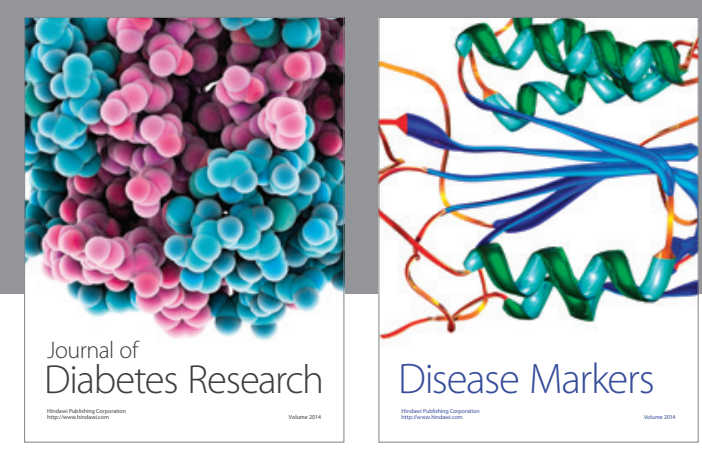

Disease Markers
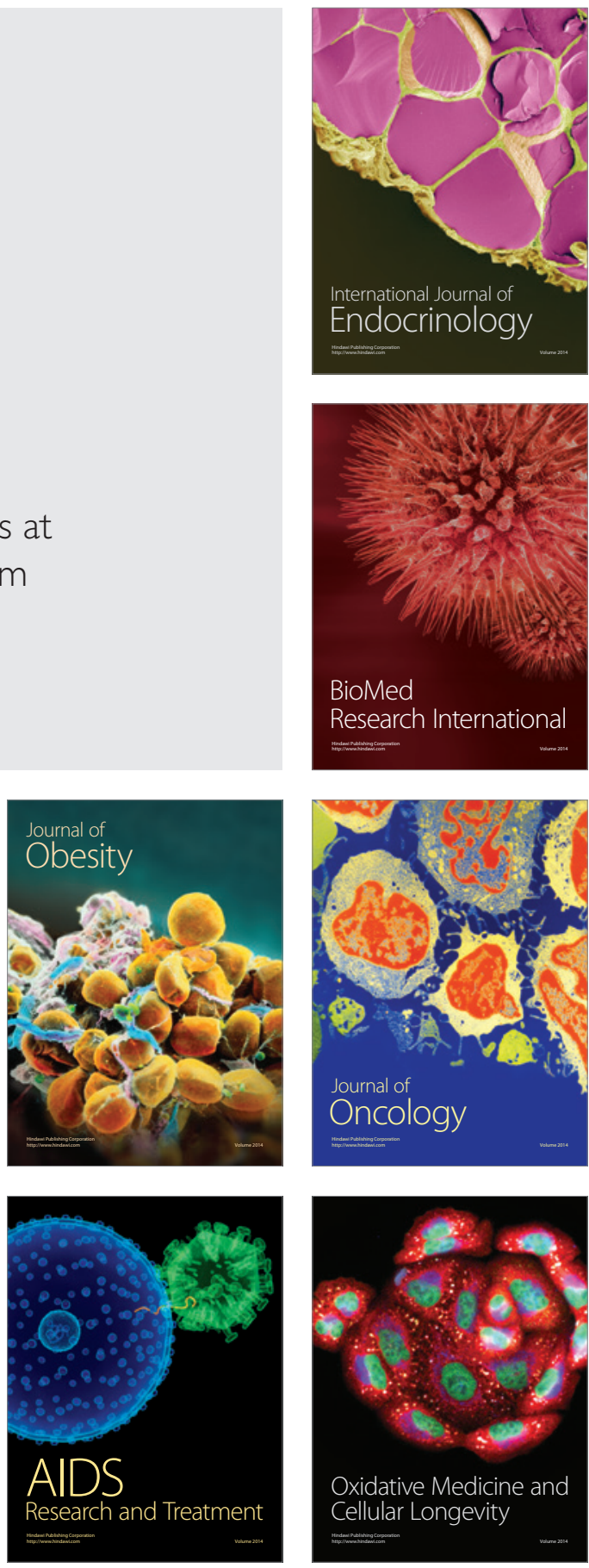